\title{
Correction to: School-University-Community Pathways to Higher Education: Teacher Perceptions, School Culture and Partnership Building
}

\author{
Enrique Alemán Jr. ${ }^{1} \cdot$ Juan A. Freire ${ }^{2,3}$ • Ashley McKinney ${ }^{3}$. \\ Dolores Delgado Bernal ${ }^{4}$
}

\section{Correction to: Urban Rev \\ DOI 10.1007/s11256-017-0424-y}

Please note that the correct surname of the first author of the this article is Alemán Jr. (not Alemán as it was given in the article as originally published).

The online version of the original article can be found under doi:10.1007/s11256-017-0424-y.

$\triangle$ Juan A. Freire

freire@byu.edu

1 Department of Educational Leadership and Policy Studies, University of Texas San Antonio, San Antonio, TX, USA

2 Department of Teacher Education, MCKB, Rm 201, Brigham Young University, Provo, UT 84602-5099, USA

3 Utah Education Policy Center, University of Utah, Salt Lake City, USA

4 Department of Chicana(o)/Latina(o) Studies and the Charter College of Education, California State University, Los Angeles, Los Angeles, USA 